\title{
Is spinal instrumentation a risk factor for late-onset infection in cases of distant infection or surgery?
}

\author{
Case report
}

\author{
Sait Naderi, M.D., Feridun Acar, M.D., ANd Tansu Mertol, M.D. \\ Department of Neurosurgery, School Of Medicine, Dokuz Eylül University, Izmir, Turkey
}

\begin{abstract}
As a cause of revision spinal surgery, spinal epidural abscess after instrumentation-assisted fusion is rare in neurosurgical practice. Postoperative infections are frequently seen in the time period soon after surgery.

The authors report on the case of a 45-year-old woman who had undergone posterior instrumentation-augmented fusion for L4-5 degenerative spondylolisthesis. Ten months after the operation she presented to the neurosurgery clinic with complaints of severe low-back pain and radicular right lower-extremity pain. She had undergone laparoscopic surgery for acute cholecystitis 1 month prior to readmission. Radiological study revealed a spinal epidural abscess in communication with a right psoas abscess at L4-5. The abscess was drained percutaneously with the aid of C-arm fluoroscopic guidance, and a 6-week course of parenteral antibiotic therapy was administered.

Retrograde lymphatic bacterial translocation, hematopoietic spread, and the suitable charectaristics in the host may facilitate the development of infection around the implant. Thus, distant surgery and infection may be a risk factor in cases in which spinal instrumentation is placed. In such cases a prolonged antibiotic therapy for distant infection after surgery is recommended.
\end{abstract}

\section{KEY WORDS • laparascopic surgery - revision spinal surgery • epidural abscess • instrumentation}

Spinal epidural abscess is an infectious disease encountered rarely in neurosurgical practice. Initially it manifests nonspecific symptoms and may lead to severe disability and even death. With early diagnosis and treatment, however, prognosis is quite good. ${ }^{2,46,9-11,17}$ First described in 1761 , little has changed in terms of symptomatology and clinical description. Reihsaus, et al. ${ }^{13}$ have published the largest study in which they performed a metaanalysis of data obtained in 915 patients. Advances in neuroimaging and improvements in antibiotic and surgical techniques have decreased the mortality and morbidity rates.

Although the exact origin of the disease is unknown, there are two known mechanisms that cause spinal epidural abscess. The first is bacteremia and hematopoietic spread. Extremity-based skin furuncles, systemic infection and bacteremia, endocarditis, and pharyngitis are also implicated. The second possible mechanism is the direct inoculation of bacteria to the region. Surgery, trauma, lumbar puncture, discography, spondylodiscitis, and neighboring skin or deep infection are examples of this mechanism. Systemic diseases such as diabetes mellitus, chronic liver failure, chronic alcohol abuse, congestive heart failure, chronic liver failure, and immunodeficiency syndromes form a suitable basis for the entity. $1,2,6,12,13$

Postsurgical spinal infection occurs in $1.9 \%$ of cases

Abbreviation used in this paper: $\mathrm{MR}=$ magnetic resonance. after conventional spinal procedures. This rate increases with the use of instrumentation. ${ }^{19,20}$ Spinal epidural abscess, one form of spinal infection, may occur 2 to 4 weeks after surgery. A late-onset spinal epidural abscess is quite rare. In this study we present the late occurrence of spinal epidural abscess occurring after a laparoscopic cholecystectomy in which instrumentation was placed.

\section{CASE REPORT}

Presentation and Examination. This 45-year-old woman was admitted to the neurosurgery clinic with severe low-back and left radicular lower-extremity pain. Neurological examination revealed a positive Laségue test in left leg at $20^{\circ}$ with no motor or sensory deficit. Sagittal MR imaging demonstrated marked Grade 2 degenerative L4-5 spondylolisthesis (Fig. 1). She underwent L-4 total laminectomy, L4-5 discectomy, and L4-5 pedicle screw fixation (Fig. 2). The peri- and postoperative periods were uneventful. She underwent third-generation parenteral cephalosporin antibiotic therapy until the 3rd postoperative day. Preoperative symptoms resolved after surgery. She was discharged 1 week postoperatively without problems. Neither chronic medical disease nor immunosuppression was present.

At outpatient control examinations 1, 3, and 6 months after surgery, she had no complaints. Ten months after surgery she returned to the neurosurgery clinic with a 3-week 


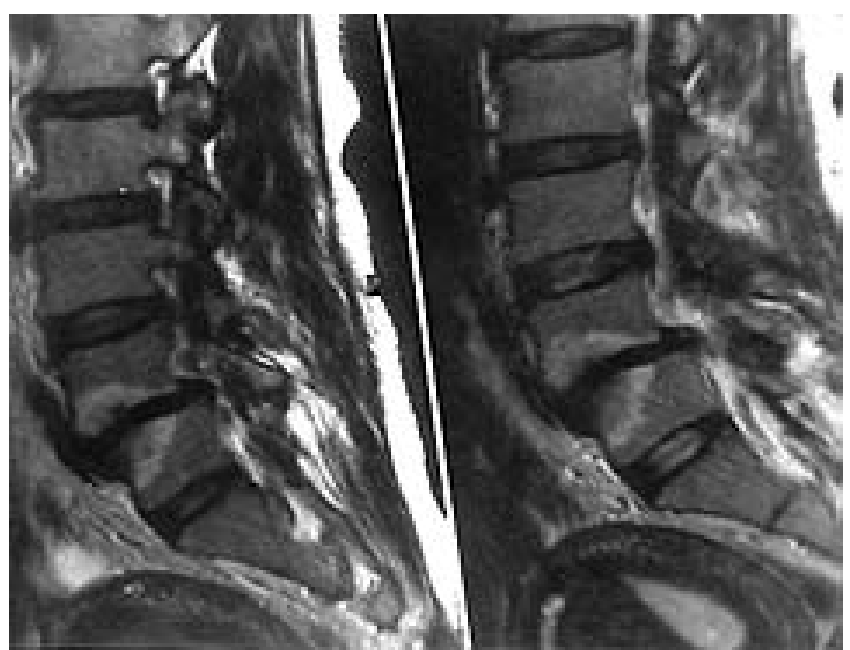

Fig. 1. Preoperative sagittal $\mathrm{T}_{2}$-weighted $\mathrm{MR}$ images revealing Grade 2 degenerative L4-5 spondylolisthesis.

history of severe back and right radicular leg pain. When questioned, the patient stated that she had undergone a laparoscopic cholecystectomy 1 month previously following an episode of acute cholecystitis. The surgery had been uneventful and she was discharged 3 days later with no complaints. She underwent a 10-day course of parenteral pre- and postoperative antibiotic therapy. One week after surgery, she experienced low-back and right radicular lower-extremity pain. The pain intensity increased progressively and 1 month after the laparoscopic surgery, the pain was intractable. Physical examination revealed no signs of infection at the lumbar operation site. The rightleg femoral stretching test was positive. There were no neurological deficits. Sagittal and axial MR imaging revealed a L4-5 spinal epidural abscess located mostly in the right lateral recess, which communicated with right psoas abscess (Fig. 3). Blood workup showed a white blood cell count of $9700 \mathrm{mmol}$ and an erythrocyte sedimentation rate of $78 \mathrm{~mm} /$ hour. In the operating theater, a local anesthetic agent was administered and the psoas abscess was percutaneously drained with the aid of fluoroscopy. Examination of the cultures was positive for coagulase-negative Staphylococcus aureus. The patient underwent a 6-week course of parenteral vancomycin therapy. In the postoperative period, her pain subsided and she was discharged without complaints. Postoperative MR imaging demonstrating no evidence of abscess in the epidural space nor in paravertebral area (data not shown).

\section{DISCUSSION}

Like any operative procedure, spinal surgery may be complicated and in turn result in morbidity or mortality. Such complications may require a revision surgery. The indications for revision after surgery for lumbar degenerative disease include infection, hardware failure, hematoma, and dural tear leading to CSF leakage. An early- or late-onset postoperative infection may require revision surgery.

Late-onset spinal epidural abscess after instrumentation-augmented spinal fusion is not common. ${ }^{3,7,14,15,16} \mathrm{Un}$ -

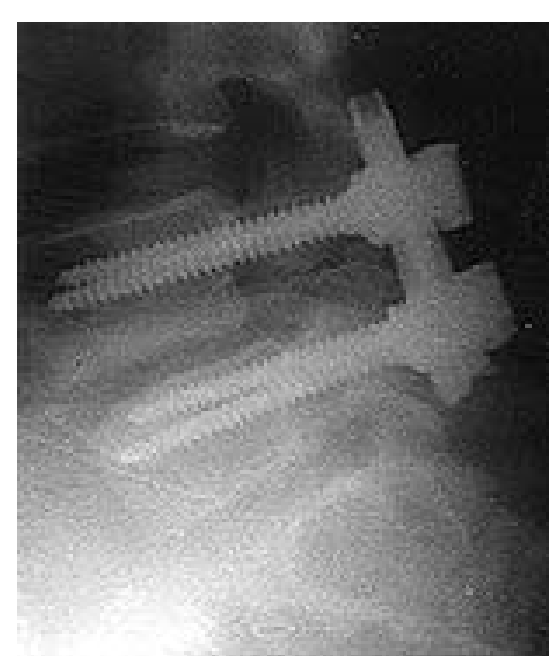

Fig. 2. Postoperative lateral radiograph demonstrating transpedicular screw and rod fixation at L4-5.

til evidence reported in recent studies, the causes of postoperative spinal epidural abscess were generally thought to be related to bacterial contamination that occurred during the operation. The infection seemed to be mainly local; however, in more studies authors have shown that the disease process has a broader base of contributing factors.

Soon after placement of spinal instrumentation, inflammatory response to fixation devices can be detected. Levels of C-reactive protein as well as erythrocyte sedimentation rate and white blood cell counts are significantly higher in patients who underwent instrumentation-augmented fusion compared with those in whom no spinal hardware was implanted. ${ }^{18}$ The levels of these inflammation markers begin to increase 6 hours after surgery and peak on the 2nd and 3rd postoperative days. Generally, normal levels are detected between the 5th and 21st days postoperatively. ${ }^{18}$ Inflammatory cells such as macrophages and monocytes make contact with the instrument surface. Metal ions are released from the instrument, and proinflammatory cytokines such as tumor necrosis factor $-\alpha$ and interleukin- $1,-6$, and -8 are released by the inflammatory cells. ${ }^{18}$ These cytokines blend into systemic circulation and trigger a subclinical systemic inflammatory response. The late postoperative progression of these cytokines in systemic circulation is not clear and needs to be studied to illuminate relation to late-onset infection.

Another interesting issue is the adherence of bacteria to the implanted hardware. Under in vitro conditions, because the surface of the metal/titanium implants is smooth, bacteria do not easily adhere. In in vivo circumstances, however, a glycocalyx biofilm layer forms on the surface of the implant following the inflammatory reaction. ${ }^{8}$ This layer facilitates the adherence of the bacteria. Additionally this layer forms a suitable medium for bacterial growth. ${ }^{8}$ In the presence of bacteremia, the hardware is always prone to bacteria-related adherence and growth that results in clinical infection.

In the presence of a bacteremia, bacteria adhere to the glycocalyx biofilm layer on the instrument and start to grow. When the vertebral anatomy is visualized, it is possible to estimate the location of the possible infection 


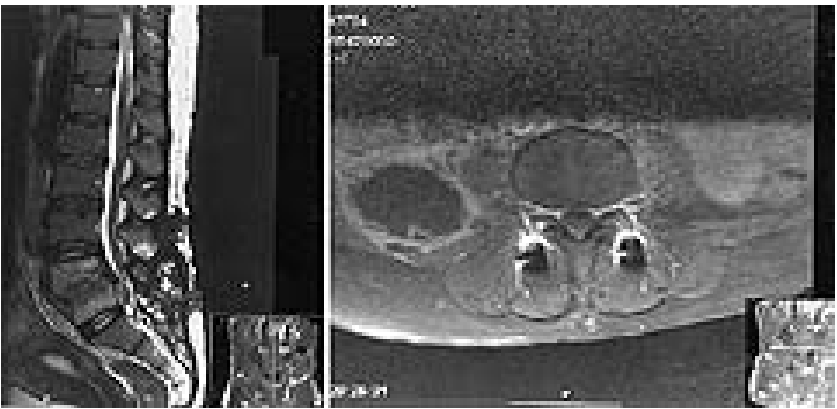

Fig. 3. Lumbar MR images. Upper: Sagittal $\mathrm{T}_{2}$-weighted image revealing a spinal epidural abscess posterior to $\mathrm{L}-5$ vertebra. Lower: Axial $\mathrm{T}_{1}$-weighted image demonstrating a right L4-5 psoas abscess at readmission.

neighboring the instrumentation. The possibilities include the vertebral body, intervertebral disc space, epidural space, dura mater, and intradural compartment (although the infection rarely spreads to the intradural compartment). Mostly, it is concentrated in the epidural space. ${ }^{19}$ The Batson venous plexus and relatively poor vascular supply in the epidural space form a suitable medium for the infection leading to epidural abscess. ${ }^{2}$

Based on the aforementioned factors, source of distant infection and distant sites of surgical intervention may cause late-onset spinal infections in cases in which instrumentation has been placed. As in our case, acute cholecystitis and/or laparoscopic surgery is the leading cause of the infection. The common point, however, is that concentrated bacteremia and retrograde bacterial lymphatic translocation cause huge numbers of bacteria to reach the instrumentation site and adhere to its surface, even in the absence of infection around the cholecystectomy area. Systemic low immunological status triggers the process but is not mandatory. In the present case it is difficult to estimate whether the spinal epidural abscess or psoas abscess was the primary pathological entity. To our knowledge, this is the first case to be reported in the literature in which there was late-onset spinal epidural abscess after acute cholecystectomy and laparoscopic instrumentationaugmented fusion.

The principles of treatment in this situation are drainage of the abscess, debridement, irrigation, and appropriate parenteral antibiotic therapy for 6 to 8 weeks. In rare cases involving resistant infections, the spinal instruments should be removed until the infection subsides. ${ }^{21}$

\section{CONCLUSIONS}

Previously placed instrumentation is a risk factor for late-onset spinal epidural abscess. In the setting of revision spinal surgery, it should be kept in mind that, distant bacteremia and spinal instrumentation may create a good medium for the bacteria to grow and cause clinical deep infection. In cases with nonspecific symptoms related to a site at which spinal instrumentation was placed, late-onset spinal epidural abscess should always be suspected. When severe systemic distant infection or distant surgical site is present in patients with prior spinal instrumentation, more serious and extended antibiotic therapy should be administered.

\section{References}

1. Bavbek M, Inci S, Tahta K, et al: Primary multiple spinal extradural hydatid cysts. Case report and review of the literature. [Corrected] Paraplegia 30:517-519, 1992

2. Baker AS, Ojemann RG, Swartz MN, et al: Spinal epidural abscess. N Eng J Med 293:463-468, 1975

3. Clark CE, Shufflebarger HL: Late-developing infection in instrumented idiopathic scoliosis. Spine 24:1909-1912, 1999

4. Del Curling O, Gower DJ, McWhorter JM: Changing concepts in spinal epidural abscess: a report of 29 cases. Neurosurgery 27:185-192, 1990

5. Feldenzer JA, McKeever PE, Schaberg DR, et al: The pathogenesis of spinal epidural abscess: microangiographic studies in an experimental model. J Neurosurg 69:110-114, 1988

6. Hlavin ML, Kaminski HJ, Ross JS, et al: Spinal epidural abscess: a ten-year perspective. Neurosurgery 27:177-184, 1990

7. Gaine WJ, Andrew SM, Chadwick P, et al: Late operative site pain with Isola posterior instrumentation requiring implant removal: infection or metal reaction? Spine 26:583-587, 2001

8. Gristina AG, Costerton JW: Bacterial adherence to biomaterials and tissue. The significance of its role in clinical sepsis. J Bone Joint Surg Am 67:264-273, 1985

9. Mackenzie AR, Laing RB, Smith CC, et al: Spinal epidural abscess: the importance of early diagnosis and treatment. J Neurol Neurosurg Psychiatry 65:209-212, 1998

10. Mooney RP, Hockberger RS: Spinal epidural abscess: a rapidly progressive disease. Ann Emerg Med 16:1168-1170, 1987

11. Naderi S, Yüceer N, Mertol T, et al: Course and prognosis of spinal epidural abscess. Report of the five cases. Eur J Orthop Surg Traumatol 10:199-202, 2000

12. Naderi S, Acar F, Arda MN: Iatrojenic epidural abscess and discitis after lumbar disc surgery: can epidural steroids be responsible for abscess formation? J Neurol Sci (Turkish) 18 (3):\#32, 2001

13. Reihsaus E, Waldbaur H, Seeling W: Spinal epidural abscess: a meta-analysis of 915 patients. Neurosurg Rev 23:175-204, 2000

14. Robertson PA, Taylor TK: Late presentation of infection as a complication of Dwyer anterior spinal instrumentation. J Spinal Disord 6:256-259, 1993

15. Spiegelmann R, Findler G, Faibel M, et al: Postoperative spinal epidural empyema. Clinical and computed tomography features. Spine 16:1146-1149, 1991

16. Soultanis K, Mantelos G, Pagiatakis A, et al: Late infection in patients with scoliosis treated with spinal instrumentation. Clin Orthop 411:116-123, 2003

17. Tacconi L, Johnston FG, Symon L: Spinal epidural abscessreview of 10 cases. Acta Neurochir 138:520-523, 1996

18. Takahashi J, Ebara S, Kamimura M, et al: Early-phase enhanced inflammatory reaction after spinal instrumentation surgery. Spine 26:1698-1704, 2001

19. Weinstein MA, McCabe JP, Cammisa FP Jr: Postoperative spinal wound infection: a review of 2,391 consecutive index procedures. J Spinal Disord 13:422-426, 2000

20. Wimmer C, Gluch H, Franzreb M, et al: Predisposing factors for infection in spine surgery: a survey of 850 spinal procedures. J Spinal Disord 11:124-128, 1998

21. Wimmer C, Gluch H: Management of postoperative wound infection in posterior spinal fusion with instrumentation. J Spinal Disord 9:505-508, 1996

\section{Manuscript received June 14, 2003.}

Accepted in final form August 19, 2003.

Address reprint requests to: Sait Naderi, M.D., Department of Neurosurgery, Dokuz Eylül University, İnciraltı, İzmir, Turkey. email: snaderi@deu.edu.tr. 